\title{
Discharge properties of identified cochlear nucleus neurons and auditory nerve fibers in response to repetitive electrical stimulation of the auditory nerve
}

Received: 26 November 2002 / Accepted: 2 July 2003 / Published online: 4 September 2003

(C) Springer-Verlag 2003

\begin{abstract}
Using the in vitro isolated whole brain preparation of the guinea pig maintained at $29^{\circ} \mathrm{C}$, we intracellularly recorded and stained cochlear nucleus $(\mathrm{CN})$ neurons and auditory nerve (AN) fibers. Discharge properties of $\mathrm{CN}$ cells and $\mathrm{AN}$ axons were tested in response to 50-ms trains of electrical pulses delivered to the AN at rates ranging from 100 to 1000 pulses per second (pps). At low stimulation rates (200-300 pps), the discharges of AN fibers and a large proportion of principal cells (bushy, octopus, stellate) in the ventral cochlear nucleus (VCN) followed with high probability each pulse in the train, resulting in synchronization of discharges within large populations of AN fibers and $\mathrm{CN}$ cells. In contrast, at high stimulation rates (500 pps and higher), AN fibers and many VCN cells exhibited "primary-like", "onset" and some other discharge patterns resembling those produced by natural sound stimuli. Unlike cells in the VCN, principal cells (pyramidal, giant) of the dorsal $\mathrm{CN}$ did not follow the stimulating pulses even at low rates. Instead, they often showed "pauser" and "build-up" patterns of activity, characteristic for these cells in conditions of normal hearing. We hypothesize that, at low stimulation rates, the response behavior of AN fibers and VCN cells is different from the patterns of neuronal activity related to normal auditory processing, whereas high stimulation rates produce more physiologically meaningful discharge patterns. The observed differences in discharge properties of AN fibers and $\mathrm{CN}$ cells at different stimulation rates can contribute to significant advantages of high- versus low-rate electrical
\end{abstract}

\footnotetext{
A. L. Babalian $(\varangle) \cdot$ E. M. Rouiller

Division of Physiology, Department of Medicine, University of Fribourg,

Rue du Musée 5, CH-1700 Fribourg, Switzerland

e-mail: Alexandre.Babalian@unifr.ch

Tel.: +41-26-3008619

Fax: +41-26-3009734

D. K. Ryugo

Departments of Otolaryngology-HNS and Neuroscience,

Johns Hopkins University,

Baltimore, MD, USA
}

stimulation of the AN used for coding sounds in modern cochlear implants.

Keywords Isolated whole brain preparation

Intracellular recording and staining - In vitro · Frequency following $\cdot$ Guinea pig

\section{Introduction}

Stimulation of the auditory nerve (AN) with trains of repetitive electrical pulses underlies the treatment of profound deafness using cochlear implants. This approach requires better understanding of physiological responses produced by artificial electrical stimulation in brain structures along the auditory pathways. Normally, acoustic signals result in relatively stereotyped activity of AN fibers, which is transformed and encoded in various discharge patterns by different cell types in the cochlear nucleus $(\mathrm{CN})$ (for a review, see Rhode and Greenberg 1992; Romand and Avan 1997; Rouiller 1997). Therefore, understanding the interaction between $\mathrm{AN}$ fibers and $\mathrm{CN}$ neurons, in conditions of artificial electrical stimulation, can be a crucial step in improving the strategy of coding sounds by electrical stimuli delivered to AN. In recent years, using various animal models, the response properties of the AN to electrical stimulation has been extensively studied both at the level of compound evoked potentials and single unit level (e.g., Kiang and Moxon 1972; Stypulkowski and Van den Honert 1984; Van den Honert and Stypulkowski 1984, 1987; Javel et al. 1987; Hartmann and Klinke 1990; Dynes and Delgutte 1992; Shepherd and Javel 1997, 1999; Haenggeli et al. 1998; Javel and Shepherd 2000; Matsuoka et al. 2000). However, less is known about the response patterns of individual $\mathrm{CN}$ neurons induced by repetitive electrical stimulation of the AN. The responses of $\mathrm{CN}$ units were studied, for instance, with continuous sinusoidal stimulation of the cochlea (Glass 1983, 1984; Clopton and Glass 1984), a strategy less commonly used in modern cochlear implants. On the other hand, studies of $\mathrm{CN}$ neuronal 
discharges elicited by trains of electrical pulses applied to the AN (Maffi et al. 1988; O'Leary et al. 1994, 1995) were mainly restricted to the dorsal CN (DCN) and only relatively low frequency pulse trains were tested (up to $400 \mathrm{pps}$ ). Meanwhile, it has been demonstrated that significant improvement in speech recognition and a more natural pattern of activity in AN fibers can be achieved using high-rate pulsatile stimulation of the AN (up to 4000-5000 pps) (Wilson et al. 1991, 1997; Boëx et al. 1996; Rubinstein et al. 1999; Litvak et al. 2001). Another limitation of the above-mentioned studies is that the $\mathrm{CN}$ unit activity was recorded extracellularly. Extracellular recording does not permit unambiguous identification of recorded cells, which is important for comparison of the specific behavior of different $\mathrm{CN}$ cell types induced by artificial (electrical) and natural (acoustic) stimuli. The assessment of the neuronal structure and pattern of synaptic activation induced by electrical stimulation of the AN can be achieved by intracellular recordings in brain slices (Wu and Oertel 1984; Oertel et al. 1990; Manis 1990; Zhang and Oertel 1993, 1994; Golding et al. 1995). However, no systematic studies of responses in CN cells produced by electrical pulse trains applied to AN were performed using this approach. Moreover, since the brain slice contains only a part of the $\mathrm{CN}$ and the integrity of the neural circuitry is necessarily not preserved, there is a strong need of addressing the issue using an intact $\mathrm{CN}$ structure. With this respect, promising results were obtained in vivo on intracellularly recorded neurons of the anteroventral CN (AVCN), although the study did not specifically assess cell responses to repetitive stimulation of the AN (Paolini and Clark 1998).

In the present work, we report the responses of individual $\mathrm{CN}$ cells and $\mathrm{AN}$ axons evoked by pulsatile electrical stimulation of the AN in the isolated whole brain (IWB) preparation of the guinea pig. This preparation combines the advantages of in vitro conditions (stable intracellular recordings, possibility to manipulate the composition of perfusion solution, etc.) with a preserved connectivity of an intact brain. We intracellularly recorded and stained individual $\mathrm{CN}$ cells and $\mathrm{AN}$ axons in order to establish their response patterns to trains of electrical pulses delivered to the AN at repetition rates ranging from 100 to 1000 pps. Part of the present results has been published in an abstract form (Babalian et al. 1999a).

\section{Materials and methods}

Isolation and maintenance of the whole brain in vitro

Experiments were performed on isolated brains of young adult guinea pigs (Cavia porcellus) of both sexes weighing 150-300 g. They were approved by the Swiss Veterinary Authorities. The methods used to isolate the brain and maintain it in vitro have been described in detail previously (Mühlethaler et al. 1993; Babalian et al. 1997). Briefly, after administration of a lethal dose of Pentobarbital (120-150 mg/kg, i.p.), the animal was perfused through the heart with cold $\left(10-12^{\circ} \mathrm{C}\right)$ physiological solution for 56 min in order to wash out the blood from the vessels and cool down the brain. The animal was then decapitated and the skull bones over the brain were removed. The isolation of the brain was completed by cutting the cranial nerves and arteries attaching the brain to the skull on the ventral side. The isolated brain was placed in the perfusion/recording chamber filled with saline at $12-13^{\circ} \mathrm{C}$ and secured in place in a ventral side up position. One of the vertebral arteries was cannulated with a metallic tube connected to the perfusion system and the other vertebral artery was ligated. At the next step, the arteries (carotids, hypophyseal, labyrinthine, spinal and some other small arteries) severed during the dissection were closed with fine knots to minimize the leakage of perfusate from the brain. Then, the temperature of the chamber and perfusion solution was gradually increased $\left(0.2^{\circ} \mathrm{C} / \mathrm{min}\right)$ to the final recording temperature of $29^{\circ} \mathrm{C}$. The perfusion rate was also progressively increased from an initial $2-2.5 \mathrm{ml} / \mathrm{min}$ to $4.5-5 \mathrm{ml} / \mathrm{min}$. The brain was perfused with a continuously bubbled $\left(95 \% \mathrm{O}_{2}\right.$ and $\left.5 \% \mathrm{CO}_{2}\right)$ solution containing (in $\mathrm{mM}$ ): $\mathrm{NaCl}: 126 ; \mathrm{NaHCO}_{3}: 26 ; \mathrm{MgSO}_{4}: 1.3$; $\mathrm{KH}_{2} \mathrm{PO}_{4}: 1.2 ; \mathrm{KCl}: 3 ; \mathrm{CaCl}_{2}: 2.4$; glucose: 15 ; dextran (MW 70000, Macrodex, Sweden): 1.5\%. Slightly modified solution without dextran was used for transcardial perfusion of the animal and initial filling of the perfusion chamber.

\section{Stimulation, recording and data processing}

The AN was stimulated with a bipolar stainless steel electrode inserted into the nerve stump. The stimulation protocol consisted of presenting rectangular (monophasic or biphasic) electrical pulses of $0.2-\mathrm{ms}$ duration in 50-ms trains with pulse rates of 100, 200, 300, 500,800 and 1000 pps. The time interval between presentation of two consecutive trains was 1-2 s. Electrical pulses were generated through a calibrated output of an isolation unit (WPI), allowing fine adjustments of stimulation intensities. Initially, the recorded units were tested with single-pulse stimulation of the AN. Single-pulse stimulation of the AN usually induced a sequence of excitatory (EPSP) and inhibitory (IPSP) postsynaptic potentials in most intracellularly recorded $\mathrm{CN}$ neurons. The amplitude of both synaptic responses usually increased with increasing stimulation intensities and EPSPs normally reached the threshold for spike generation. Further increase of stimulation intensity, however, could still increase the amplitude of the following IPSP. Thus, the stimulation intensity was increased until the response reached its maximum and saturated. When recording intra-axonally from AN and trapezoid body (TB) fibers (see below), a progressive increase of single-pulse stimulation intensity resulted in a spike discharge in the recorded axon. The final stimulation intensity was set approximately at 1.5 times the threshold intensity. These maximal stimulation intensities, which usually did not exceed $300 \mu \mathrm{A}$, were applied in the protocol using trains of repetitive pulses.

Intracellular and intra-axonal recordings were made by micropipettes filled with a $1-2 \%$ solution of a tracer (neurobiotin or biocytin) in $2 \mathrm{M} \mathrm{K}$-acetate (resistance 120-200 M $\Omega$ ). The activity of neurons in the posteroventral CN (PVCN) and DCN was recorded by direct somatic impalements in the $\mathrm{CN}$. In contrast, since the anterior part of $\mathrm{CN}$ was inaccessible in the present experiments, the activity of neurons in the AVCN was assessed through intra-axonal recordings in the TB. Further staining of TB axons and retrograde transport of the tracer allowed us, in many cases, to determine the exact location of cells in the $\mathrm{CN}$ and to identify the cell type. Usually, the TB axons were impaled at a distance of approximately 1-2 $\mathrm{mm}$ from the $\mathrm{CN}$. In addition, in some experiments, we recorded intra-axonally the activity of individual $\mathrm{AN}$ fibers. At the end of the recording session, neurons and axons were iontophoretically injected with the tracer by passing positive currents of $0.5-1.5 \mathrm{nA}$ for 5-30 $\mathrm{min}$ (200 ms on/off). After each successful experiment, the brain was fixed with a solution of $4 \%$ paraformaldehyde in $0.1 \mathrm{M}$ phosphate buffer. Injected cells were visualized on frontal brain sections (100- $\mu$ m thickness) using standard ABC histochemistry (Wan et al.1992) and reconstructed using a drawing tube attached to a microscope.

The recorded signals were stored on videotapes using NeuroCorder interface (NeuroData). For each cell, a set of 10-50 trials 
was recorded for both the single-pulse AN stimulation and each tested frequency of pulse trains. The signals were replayed off-line, digitized and processed with ACQUI software (SICMU, Geneva, Switzerland) for display and analysis of raw data. In addition, a custom-made program on a Macintosh computer allowed us to display discriminated spikes in the form of dot rasters and peristimulus time histograms (PSTH). The ability of a unit to follow repetitive pulses was evaluated quantitatively by computing the so-called "entrainment" parameter, defined as the total number of generated spikes divided by the total number of stimulating pulses delivered to the AN. In addition, for some groups of cells, the probability of spike discharges was calculated at discrete time points within the duration of the pulse train. Limitations of our acquisition system (time resolution of $0.5 \mathrm{~ms}$ ) did not allow us to compute precisely the synchronization of discharges with respect to each pulse of the train in the form of period or interspike interval histograms, particularly at high stimulation rates.

\section{Results}

Altogether, the activity of 84 cells in the $\mathrm{CN}$ and seven AN fibers was recorded in 54 IWB preparations. Fortyfour of the 84 recorded $\mathrm{CN}$ units were recovered on histological sections and identified as bushy (7), stellate (26), octopus (2), giant (5), pyramidal (3), and vertical (1) cells. The identity of four cells could not be determined due to incomplete staining, but their location in the $\mathrm{CN}$ was mapped.

Figure 1 illustrates a typical example of recording from an axon in the TB. After staining, the axon was traced back to the $\mathrm{CN}$ and found to arise from a cell in the AVCN (Fig. 1C). Although the dendritic tree was not completely stained, the neuron was identified as bushy cell by virtue of its "clustered" branch points (Fig. 1D). Responses of the cell to AN stimulation with pulse trains of increasing rates showed that a spike was elicited for nearly every pulse in the train up to rates of $300 \mathrm{pps}$, whereas at higher rates $(500,800 \mathrm{pps})$ cell discharges did not follow each individual pulse (Fig. 1A). The ability of the cell to follow pulses in the train is better illustrated on an "entrainment" plot (Fig. 1B). It should be noted that the IWB preparation was maintained at $29^{\circ} \mathrm{C}$, which necessarily resulted in broader action potentials, increased response latencies and increased refractory periods in comparison to in vivo conditions. Therefore, since responses of $\mathrm{CN}$ cells are driven by the activity in AN fibers, it was important to compare response patterns of $\mathrm{CN}$ cells and $\mathrm{AN}$ axons in the same experimental conditions. This circumstance prompted us to record from individual AN fibers and test their responses to pulse trains delivered through the stimulating electrode in the AN. Seven AN afferent fibers were recorded and stained intra-axonally. The response pattern of AN fibers to pulse trains of increasing rates is shown in Fig. 2 (top panel) as a discharge probability, within the train time window, pooled, and averaged for all recorded AN fibers. Discharges of AN fibers followed stimulation rates up to $300 \mathrm{pps}$. At higher rates, AN fibers always fired in response to the first pulse in the train (probability equals to 1 ), after which the discharge probability rapidly decreased and reached a plateau at 0.5 and 0.15 for
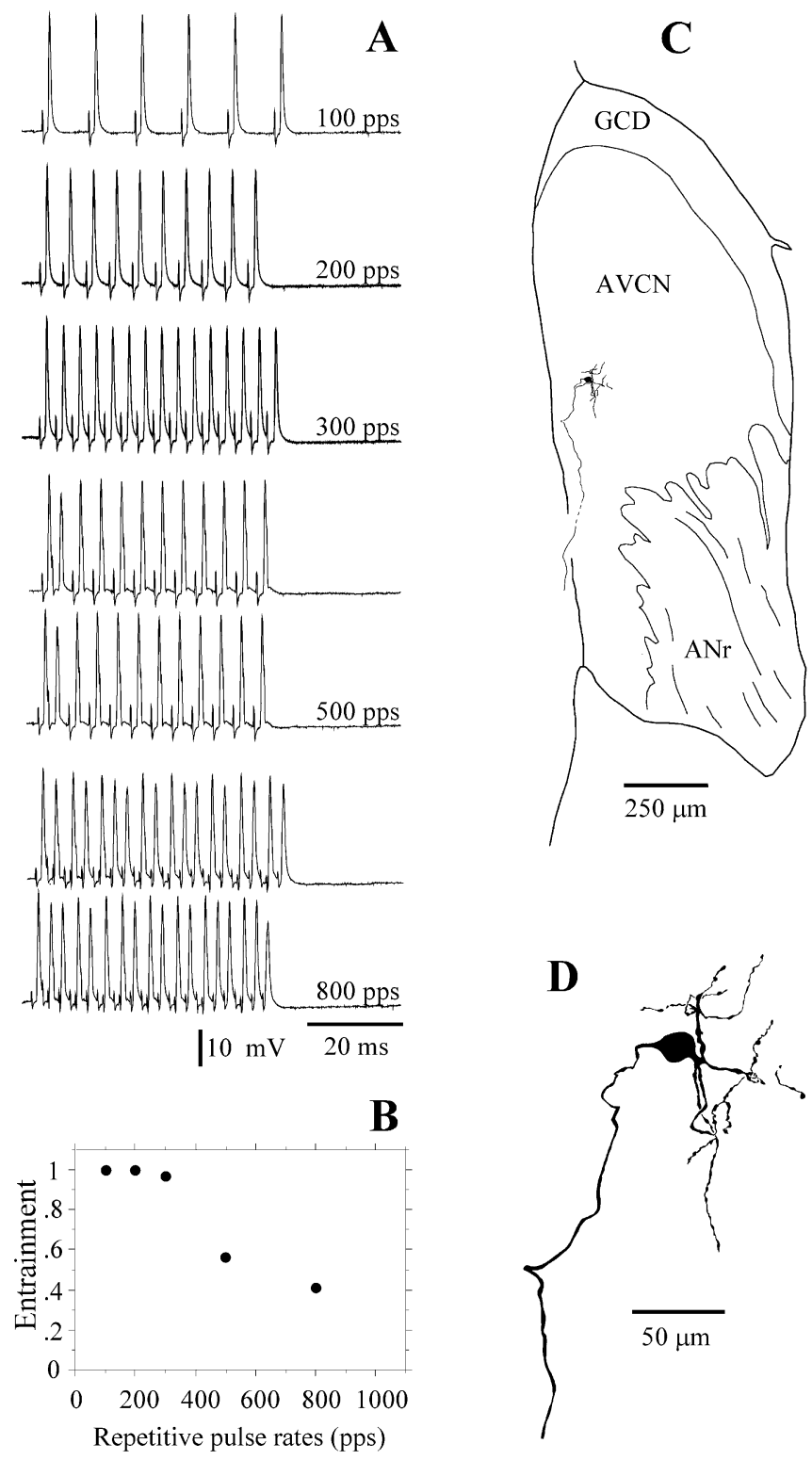

Fig. 1A-D Physiological and morphological characterization of a bushy cell in the AVCN, recorded and stained through an intraaxonal impalement in the TB. A Intra-axonal responses to electrical stimulation of the AN with trains of pulses at rates from 100 to $800 \mathrm{pps}$. Superposition of several traces at stimulation rates of 100 , 200 and 300 pps shows reproducible spike discharges of the cell to each pulse in the train. Responses at stimulation rates of 500 and $800 \mathrm{pps}$ are illustrated as two individual traces for each frequency. Stimulation rate of 1000 pps was not tested in this cell. Note that at high stimulation rates $(500,800 \mathrm{pps})$ the spike waveforms can be distorted by superimposed stimulation artifacts. The resting membrane potential of the axon was $-68 \mathrm{mV}$. B Plot illustrating the entrainment of the cell at different stimulation rates. C Location of the cell on a frontal section through the AVCN, with the axon of the cell leaving the $\mathrm{CN}$ in direction of the TB. $G C D$ granule cell domain, $A N r$ auditory nerve root. D High-magnification reconstruction of the cell 

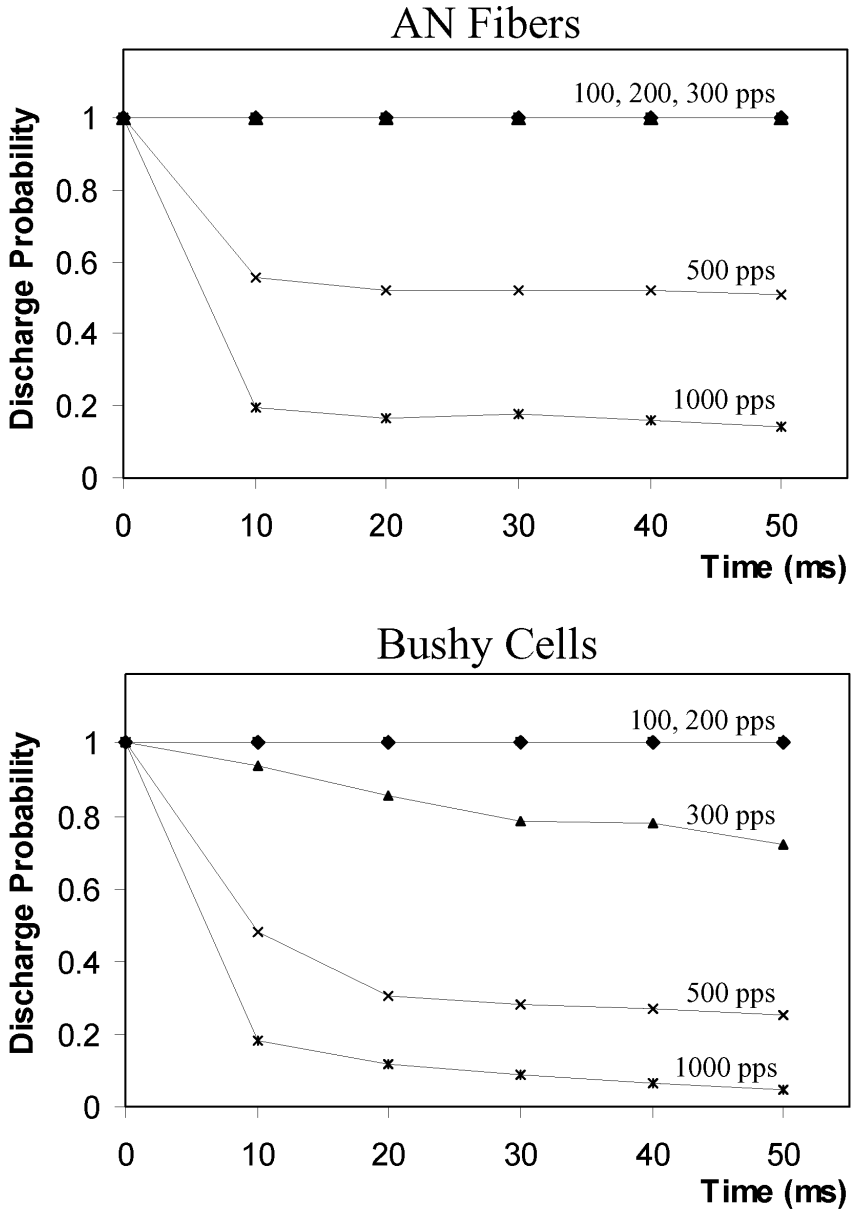

Fig. 2 Average discharge probability of AN fibers and bushy cells within the time window of the stimulation train at different pulse rates. The probability at time "0" corresponds to the discharge probability to the first pulse in the train. The following probability values were calculated for each subsequent epoch of $10 \mathrm{~ms}$ as a number of spikes divided by number of stimulation pulses within the epoch

stimulation rates of 500 and 1000 pps, respectively. Usually, the discharge of AN fibers was regular at $500 \mathrm{pps}$, with spikes generated by every other pulse in the train. Spike intervals became more random at a rate of $1000 \mathrm{pps}$, as judged from visual inspection of spike raster histograms and intracellular traces, with a slight tendency of cells to generate more spikes at the beginning of the train. Comparable firing behavior was observed for bushy cells (Fig. 2, lower panel), with a rapid adaptation of their discharge rate after the beginning of stimulation at high rates. Thus, despite some variability across units, the overall pattern of discharges in AN fibers and bushy cells became "primary-like," as reflected by discharge rate adaptation at high stimulation frequencies. The general frequency following properties for all units classified on the basis of cell type or location in the $\mathrm{CN}$ are illustrated as entrainment plots in Figs. 3 and 4, respectively.

The octopus cells, like bushy cells, were able to follow each pulse in the train up to 200 pps (Figs. 3 and 6B). At higher rates (300, 500 pps), octopus cells typically exhibited an adaptation pattern similar to that of bushy cells and AN fibers, which was transformed into an "on" response (response only to the first pulse in the train) at the highest rate tested (1000 pps, Fig. 6B).

The group of stellate cells, located for the most part in the PVCN but also in the AVCN and granule cell domain (one cell), was the most heterogeneous in term of response patterns to train stimulation of the AN. The average entrainment plot shows that, in general, discharges of stellate cells followed individual train pulses slightly less well than bushy and octopus cells (Fig. 3). Our recordings in the PVCN and AVCN (Babalian et al. 1999b, 2002) have demonstrated that, in stellate cells, stimulation of the AN usually induces a sequence of EPSP and IPSP with spike discharges driven by monosynaptic EPSPs. However, the contribution of IPSPs can vary considerably from one cell to the next, resulting in a large spectrum of responses, from pure EPSPs to large hyperpolarizing potentials following the EPSPs. This response variability of stellate cells to single pulse AN stimulation probably underlies different response patterns of these cells to train stimulation of the AN, as observed in the present study. In many stellate cells, with predominating excitatory input, spike discharges could follow each pulse in the train at low rates $(100,200 \mathrm{pps})$ and exhibited adaptation at higher rates (300, 500, 1000 pps; Fig. 6A). Some other stellate cells, with strong inhibitory inputs, exhibited adaptation pattern or even only "on" responses already at low pulse rates (not shown).

In sharp contrast was the behavior of pyramidal and giant cells in the DCN, characterized by poor entrainment even at low rates (Fig. 3). Such a behavior could be explained by their pattern of synaptic responses to AN stimulation, illustrated for a typical pyramidal cell in Fig. 5. Stimulation of the AN induced a monosynaptic EPSP followed by a large (sometimes over $10 \mathrm{mV}$ in amplitude) disynaptic IPSP, which often shunted the initial EPSP and the spike generated by the EPSP (Fig. 5A, top traces). Stimulation of the AN with trains of pulses resulted in a series of hyperpolarizing responses or cumulative hyperpolarization of the cell with no or very rare spikes during the train (Fig. 5A, 100- and 200pps stimulation traces). Another typical feature of the synaptic response of pyramidal and giant cells to AN stimulation was the presence of rebound depolarization and spike discharges that followed the IPSP (Fig. 5A, top traces). When trains of pulses were applied to the AN, this property of synaptic response often resulted in recovery of spike discharges in the cell towards the end of the train and almost always resulted in discharges after the offset of the train (Fig. 5A, 100- and 200-pps stimulation traces). The afterdischarge usually became stronger as the stimulation rate increased. When represented as PSTH, these specific response patterns of pyramidal and giant cells to train stimulation of the AN appeared as "pauser" (Fig. 6C), "build-up" and "on-off" response profiles. 

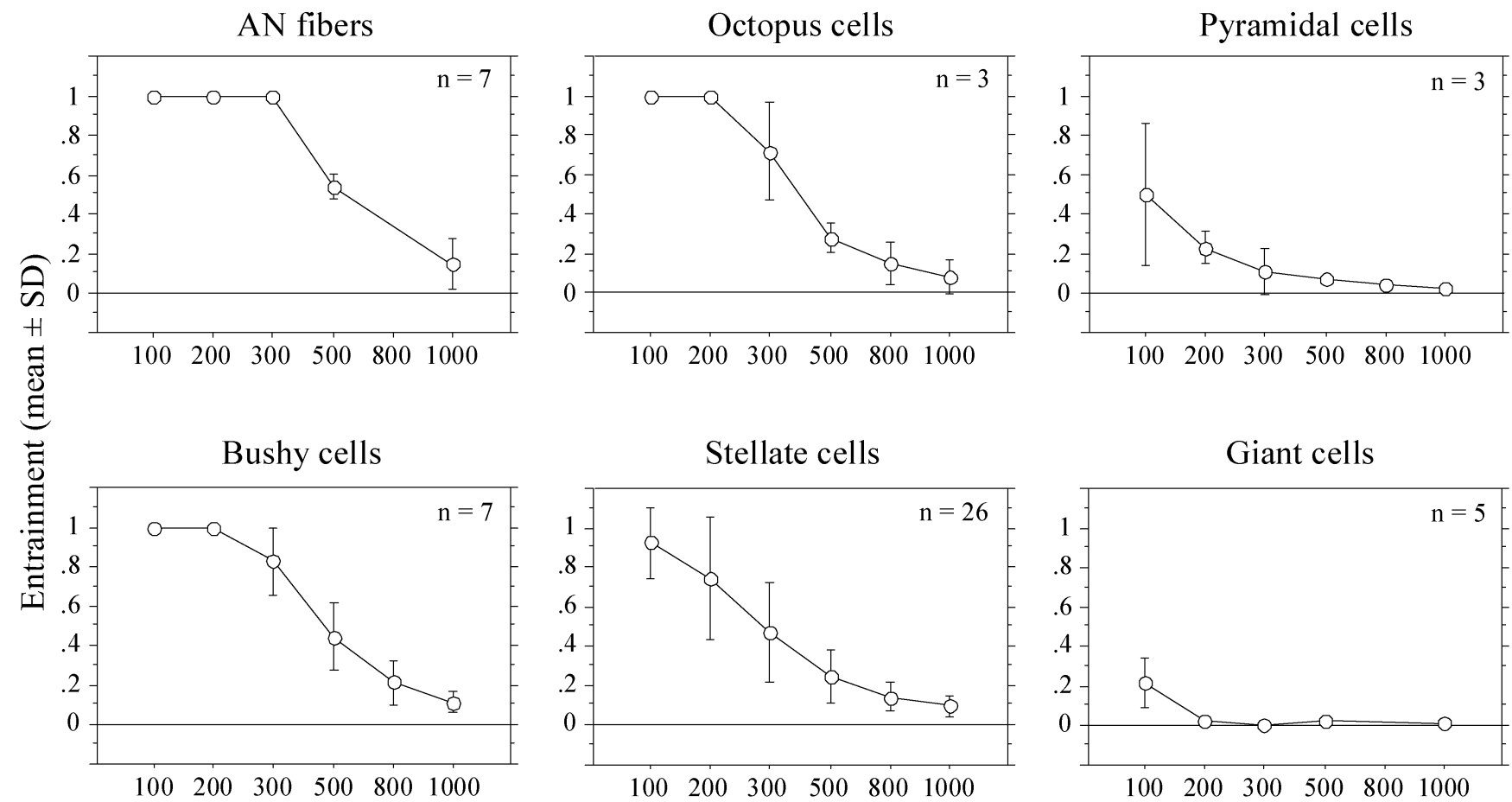

Repetitive pulse rates (pps)

Fig. 3 Average entrainment plots for $\mathrm{AN}$ fibers and identified principal cell types in the $\mathrm{CN}$ tested with train stimulation of the AN. Each point on the plots is the mean entrainment \pm standard deviation. The plot for octopus cells includes one unit which was

\section{Discussion}

Improvement of strategies of coding acoustic signals by electrical pulses applied to the AN in modern cochlear implants requires predictable control of the neuronal activity along the auditory pathways produced by electrical stimulation. More natural sound percepts may be obtained in cochlear implant patients if the parameters of electrical stimuli are adjusted to match the type of activity normally produced by environmental (acoustic) stimulation. Along this line, the present results contribute to a better understanding of the transformation of information from AN fibers to $\mathrm{CN}$ neurons induced by trains of repetitive electrical pulses. A comparison of our data with AN-CN relations in conditions of normal acoustic processing, derived from PSTH profiles, supports the notion that electrical stimulation at high rates produces neuronal activity closer to the natural patterns of neuronal activity than electrical stimulation delivered at low rates.

Stimulation of the AN with trains of electrical pulses at low rates (up to 200-300 pps) resulted in action potentials in AN fibers for each individual pulse, corresponding to an entrainment of $100 \%$. Such activity, with high probability of discharge to each stimulating pulse, was transferred to a large proportion of principal neurons (bushy, stellate, octopus) in the AVCN and PVCN. Similar findings were reported in cats in vivo for ventral not recovered on histological sections but exhibited a very specific "gradual spike" response pattern to AN stimulation, characteristic of octopus cells (Golding et al. 1995; our data). No entrainment plot is shown for the only vertical cell recorded in the present study

CN (VCN) cells and some DCN neurons, which could follow trains of electrical pulses delivered at rates of 200 $400 \mathrm{pps}$ and, less frequently, at higher (800 pps) rates (Maffi et al. 1988; O'Leary et al. 1995). Such high entrainment in the $\mathrm{CN}$ is consistent with the observation that, in vivo, AN fibers can follow rates up to $800 \mathrm{pps}$ with high temporal precision (Shepherd and Javel 1997). These data derived from electrical stimulation of the AN resemble observations obtained in $\mathrm{AN}$ and $\mathrm{CN}$ units in response to repetitive acoustic pulses (Moeller 1969). In the IWB preparation, maximal stimulation rates, at which highest entrainment levels can be achieved, are considerably lower than in in vivo conditions due to the lower temperature $\left(29^{\circ} \mathrm{C}\right)$ at which the present experiments were conducted. Nevertheless, in vitro and in vivo data demonstrate that electrical pulses delivered to the $\mathrm{AN}$ at low rates (200-400 pps) induce strong entrainment in CN neurons. It must be noted that, in our experiments, the ratio of highest stimulation rates tested (1000 pps) to the maximal rate that could be followed by AN fibers (300$350 \mathrm{pps}$ ) was approximately $3-3.5$. This value matches fairly well the ratio of highest stimulation rates used in many modern cochlear implants (up to $4000 \mathrm{pps}$ ) to the upper rate limit that could be followed by AN fibers in vivo (800-1000 pps). For this reason, in the present study the highest stimulation rate was set at 1000 pps. 

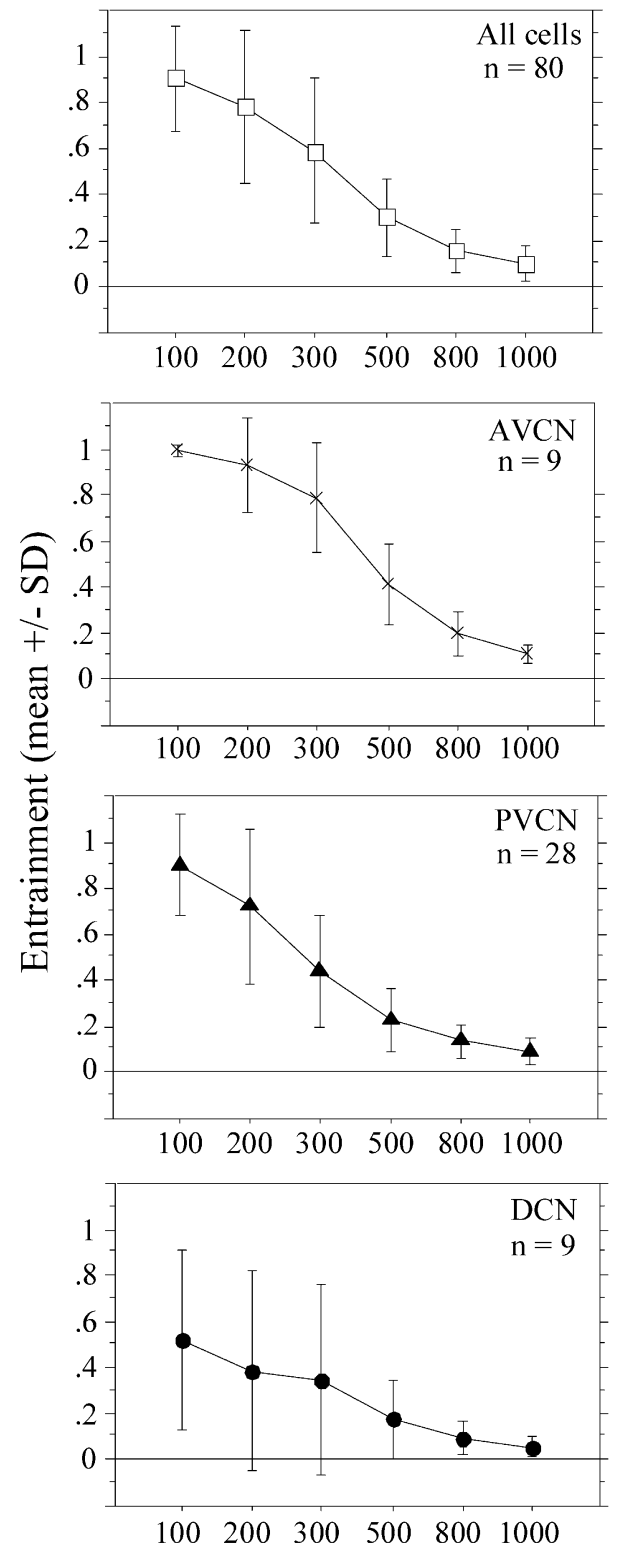

Repetitive pulse rates (pps)

Fig. 4 Entrainment plots for all $\mathrm{CN}$ units and groups of cells classified according to their location within the three $\mathrm{CN}$ subdivisions. Note that the frequency following ability of cells gradually decreases from the AVCN to PVCN and to DCN

A direct comparison of responses in the $\mathrm{VCN}$ to pulsatile acoustic (clicks) and electrical stimuli delivered in trains of $250 \mathrm{~ms}$ to the same ear has been derived from near-field chronic recordings (Loquet et al., this volume). For both types of stimuli, the amplitude of the response to each individual pulse decreased progressively along the train, corresponding to a phenomenon of adaptation. At low stimulation rates $(<400 \mathrm{pps})$, the adaptation was significantly more pronounced for clicks than for electrical pulses. At higher stimulation rates (800-1000 pps), the adaptation was more comparable for both types of stimuli (Loquet et al., unpublished data). The similarity of
A
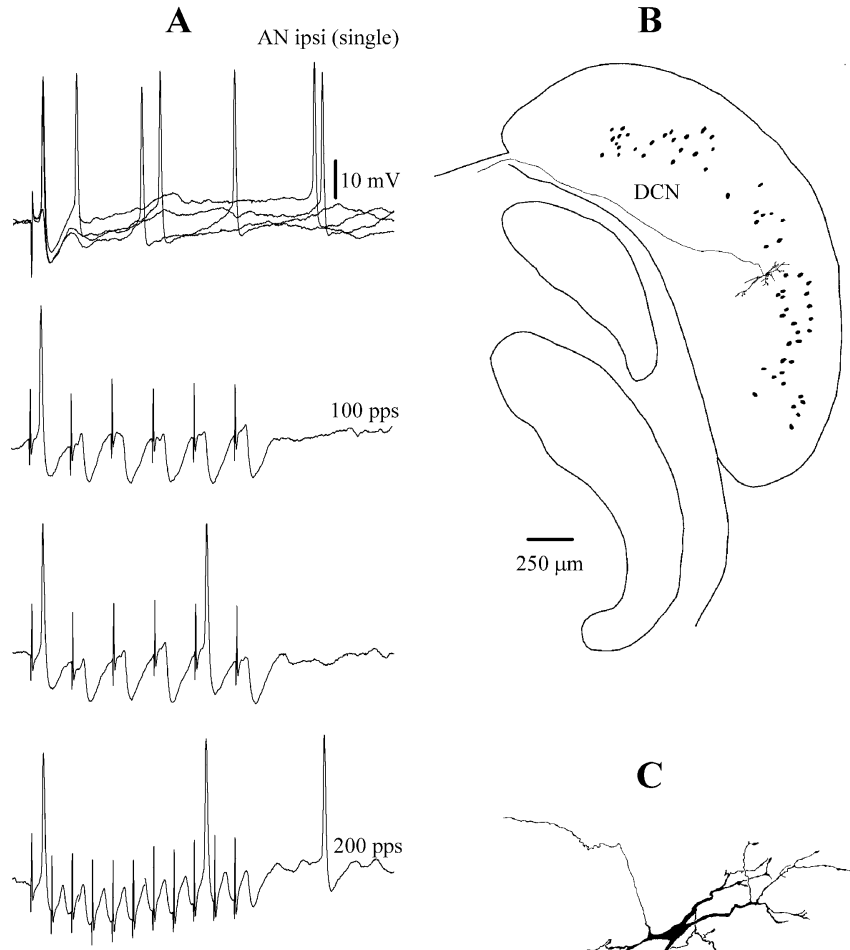

C

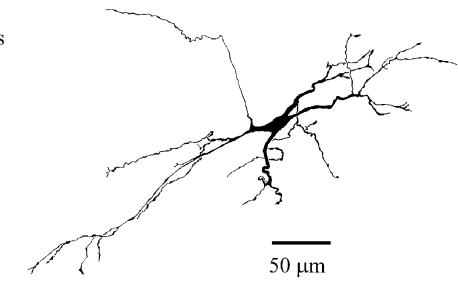

B 

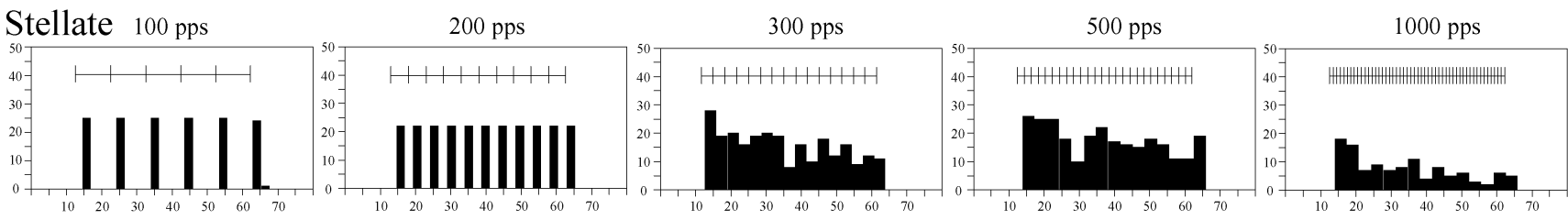

Octopus
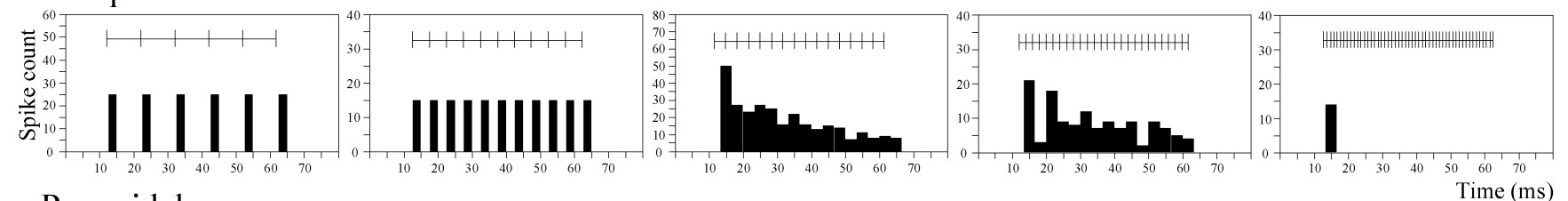

Pyramidal

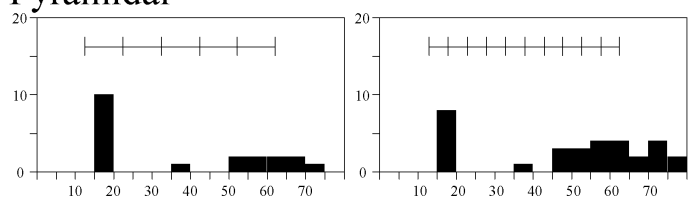

Fig. 6 PSTHs illustrating a discharge pattern of a stellate, octopus and pyramidal cell in response to electrical stimulation of the AN at various rates. The stimulation train pattern and timing is schematically shown in each panel on the top. Different bin widths were

used in different PSTHs in order to optimally show the overall response envelope. The spike count scale was adapted for each PSTH because of different number of trials tested. See the text for the details of discharge patterns

stimuli and thus reduce the difference between normal and "electrical" hearing (Rubinstein et al. 1999; Litvak et al. 2001).

Other possible benefits of high stimulation rates for coding signals in cochlear implants derive from the present study of discharge patterns of $\mathrm{CN}$ neurons to electrical stimulation of the AN at high rates, together with identification of the corresponding cell types. It is known that short tone bursts produce stereotyped "primary-like" responses in individual AN fibers. Primarylike responses are then transformed into various specific patterns of discharge in $\mathrm{CN}$ neurons. The major discharge patterns of CN cells include "primary-like", "on" ("onset"), "chopper", "pauser" and "build-up" responses (Pfeiffer 1966; Godfrey et al. 1975a, b; Rhode et al. 1983a, b; Blackburn and Sachs 1989; for reviews, also see Rhode and Greenberg 1992; Rouiller 1997; Romand and Avan 1997). Some of these response types can be further classified into subtypes depending on the peculiarities of the discharge or variability of some discharge components. In addition, some response types can emerge by varying the bin width used to construct the PSTH (Shofner and Young 1985). Although various discharge patterns can be observed in the three $\mathrm{CN}$ subdivisions, there are predominating patterns of discharge associated to different $\mathrm{CN}$ subdivisions. It is well documented that "primary-like", "on" and "chopper" response patterns mainly characterize cells in the AVCN and PVCN (Pfeiffer 1966; Godfrey et al. 1975a; Rhode et al. 1983a; Shofner and Young 1985; Blackburn and Sachs 1989). On the other hand, "pauser", "build-up" and similar response patterns are predominantly found in the DCN (Pfeiffer 1966; Godfrey et al.1975b; Rhode et al. 1983b; Shofner and Young 1985).

It should be noted that due to relatively large bins and small number of trials used to construct our PSTH, the very fine discharge profiles (like "chopper" and some other patterns) could not be determined in our study. Nevertheless, the overall response shapes observed at high stimulation rates indicate that $\mathrm{AN}$ fibers and neurons in the AVCN and PVCN produced discharge patterns resembling those evoked by natural tonal stimulation. For instance, the behavior of AN fibers and bushy cells progressively showed a transformation towards "primarylike" for stimulation rates of $500 \mathrm{pps}$ and higher. Similarly, octopus cells exhibited both "primary-like" and "on" response patterns when stimulated at high rates. Finally, stellate cells showed various patterns of discharge at high stimulation rates, including "primary-like", "on", and some other response types. The present data are consistent with previous studies correlating physiological response properties of $\mathrm{CN}$ cells with their morphology. It has been demonstrated that the majority of bushy cells exhibited "primary-like" responses to sound stimuli (Rhode et al.1983a; Rouiller and Ryugo 1984). Octopus cells tended to be associated with "on" response patterns (Godfrey et al. 1975a; Rhode et al. 1983a; Rouiller and Ryugo 1984). Finally, a large spectrum of physiological response patterns was attributed to stellate (multipolar) cells in the AVCN and PVCN (Godfrey et al. 1975a; Rhode et al. 1983a; Shofner and Young 1985).

Unlike cells in the AVCN and PVCN, discharges of pyramidal and giant neurons in the DCN did not follow stimulation pulses even at low rates. Instead, they often exhibited a specific discharge pattern, described mainly as "pauser" and "build-up" response categories. The "pauser" and "build-up" patterns of activity were consistently reported for giant and pyramidal cells in vivo in response to sounds (Rhode et al. 1983b; Shofner and Young 1985). 
A similar type of activity could be recorded extracellularly from DCN cells in response to single-pulse and train electrical stimulation (Shofner and Young 1985; O'Leary et al. 1994, 1995). It has been proposed that membrane properties of pyramidal neurons can underlie these specific response patterns (Manis 1990; Kanold and Manis 2001). Our data indicate that specific sequence of excitatory and large inhibitory synaptic responses, together with the following rebound depolarization, produced in pyramidal and giant cells by activation of the $\mathrm{AN}$ are sufficient to explain their discharge pattern. This interpretation is corroborated by previous intracellular recordings in vivo of the specific synaptic response patterns of pyramidal cells to sound stimuli (Rhode et al.1983b).

Collectively, our data provide new insights into possible advantages of high- versus low-rate electrical stimulation of the AN for encoding sounds. It appears that low-rate electrical stimulation of the AN results in high entrainment of large populations of AN fibers and cells in the AVCN and PVCN. Such response behavior is different from the patterns of neuronal activity in the $\mathrm{AN}$ and VCN related to normal auditory processing. In contrast, high stimulation rates produce more physiologically meaningful discharge patterns in cells in the AVCN and PVCN than low stimulation rates. Moreover, different cell types can produce similar discharge patterns in response to sound stimuli and electrical stimulation of the $\mathrm{AN}$ at high rates. Although principal DCN cells can exhibit physiologically relevant discharge patterns even at low stimulation rates, it is well established that the VCN and its output through the TB are crucially involved in basic auditory functions (Masterton and Granger 1988; Masterton et al. 1994).

Even if our data are in accordance with recent findings indicating that electrical stimulation at high rates may provide better conditions for sound coding in cochlear implants, it should be noted that other stimulation strategies are still used, though much less frequently, in clinical practice. In addition, our present results must be interpreted with caution for two reasons. First, the comparison of our results with data obtained in vivo is based only on characterization of discharge patterns in the form of PSTH profiles and was derived from limited samples of different cell types. Second, in our experiments, the electrical stimulation was applied to the whole $\mathrm{AN}$ and, thus, was tonotopically non-specific. In contrast, the electrical stimulation in cochlear implants partially preserves the selective activation of spatially separated frequency channels specific for normal acoustic processing. Further experiments and data analyses would be needed for better characterization of the behavior of identified $\mathrm{CN}$ cells in response to pulsatile electrical stimulation of the AN.

Acknowledgements This work was supported by Swiss National Science Foundation grants 31-55836.98 and 31-66731.01, NIH/ NIDCD grant DC00232, and the Swiss national center for competence in research (NCCR) "Neural plasticity and repair."

\section{References}

Babalian AL, Vibert N, Assie G, Serafin M, Mühlethaler M, Vidal PP (1997) Central vestibular networks in the guinea-pig: functional characterization in the isolated whole brain in vitro. Neuroscience 81:405-426

Babalian AL, Ryugo DK, Rouiller EM (1999a) Intracellular responses of identified neurons in the cochlear nucleus to electrical stimulation of auditory nerves: an in vitro whole brain study (Abstract). Assoc Res Otolaryngol 22:143

Babalian AL, Ryugo DK, Vischer MW, Rouiller EM (1999b) Inhibitory synaptic interactions between cochlear nuclei: evidence from an in vitro whole brain study. Neuroreport 10:1913-1917

Babalian AL, Jacomme AV, Doucet JR, Ryugo DK, Rouiller EM (2002) Commissural glycinergic inhibition of bushy and stellate cells in the anteroventral cochlear nucleus. Neuroreport 13:555-558

Blackburn CC, Sachs MB (1989) Classification of unit types in the anteroventral cochlear nucleus: PST histograms and regulatory analysis. J Neurophysiol 62:1303-1329

Boëx C, Pelizzone M, Montandon P (1996) Speech recognition with a CIS strategy for the Ineraid multichannel cochlear implant. Am J Otol 17:61-68

Clopton BM, Glass I (1984) Unit responses at cochlear nucleus to electrical stimulation through a cochlear prosthesis. Hear Res $14: 1-11$

Dynes SBC, Delgutte B (1992) Phase-locking of auditory-nerve discharges to sinusoidal electric stimulation of the cochlea. Hear Res 58:79-90

Glass I (1983) Tuning characteristics of cochlear nucleus units in response to electrical stimulation of the cochlea. Hear Res $12: 223-237$

Glass I (1984) Phase-locked responses of cochlear nucleus units to electrical stimulation through a cochlear implant. Exp Brain Res 55:386-390

Godfrey DA, Kiang NYS, Norris BE (1975a) Single unit activity in the posteroventral cochlear nucleus of the cat. J Comp Neurol 162:247-268

Godfrey DA, Kiang NYS, Norris BE (1975b) Single unit activity in the dorsal cochlear nucleus of the cat. J Comp Neurol 162:269284

Golding NL, Robertson D, Oertel D (1995) Recordings from slices indicate that octopus cells of the cochlear nucleus detect coincident firing of auditory nerve fibers with temporal precision. J Neurosci 15:3138-3153

Haenggeli A, Zhang JS, Vischer MW, Pellizone M, Rouiller EM (1998) Electrically evoked compound action potential (ECAP) of the cochlear nerve in response to pulsatile electrical stimulation of the cochlea in the rat: effects of stimulation at high rates. Audiology 37:353-371

Hartmann R, Klinke R (1990) Response characteristics of nerve fibers to patterned electrical stimulation. In: Miller JM, Spelman FA (eds) Cochlear implants: models of the electrically stimulated ear. Springer, Berlin Heidelberg New York, pp 135160

Javel E, Shepherd RK (2000) Electrical stimulation of the auditory nerve. III. Response initiation sites and temporal fine structure. Hear Res 140:45-76

Javel E, Tong YC, Shepherd RK, Clark GM (1987) Responses of cat auditory nerve fibers to biphasic electrical current pulses. Ann Otol Rhinol Laryngol 96[Suppl 128]:26-30

Kanold PO, Manis PB (2001) A physiologically based model of discharge pattern regulation by transient $\mathrm{K}+$ currents in cochlear nucleus pyramidal cells. J Neurophysiol 85:523-538

Kiang NYS, Moxon EC (1972) Physiological considerations in artificial stimulation of the inner ear. Ann Otol Rhinol Laryngol 81:714-731

Litvak L, Delgutte B, Eddington D (2001) Auditory nerve fiber responses to electric stimulation: modulated and unmodulated pulse trains. J Acoust Soc Am 110:368-379 
Maffi CL, Tong YC, Clark GM (1988) Responses of cat ventral cochlear nucleus neurones to variations in the rate and intensity of electric current pulses. In: Syka J, Masterton RB (eds) Auditory pathways-structure and function, 2nd edn. Plenum Press, New York, pp 149-154

Manis PB (1990) Membrane properties and discharge characteristics of guinea pig dorsal cochlear nucleus neurons studied in vitro. J Neurosci 10:2338-2351

Masterton RB, Granger EM (1988) Role of the acoustic striae in hearing: contribution of dorsal and intermediate striae to detection of noises and tones. J Neurophysiol 60:1841-1860

Masterton RB, Granger EM, Glendenning KK (1994) Role of the acoustic striae in hearing: mechanism for enhancement of sound detection in cats. Hear Res 73:209-222

Matsuoka AJ, Abbas PJ, Rubinstein JT, Miller CA (2000) The neuronal response to electrical constant-amplitude pulse train stimulation: evoked compound action potential recordings. Hear Res 149:115-128

Moeller AR (1969) Unit responses in the rat cochlear nucleus to repetitive transient sounds. Acta Physiol Scand 75:542-551

Mühlethaler M, De Curtis M, Walton K, Llinás R (1993) The isolated and perfused brain of the guinea-pig in vitro. Eur $\mathbf{J}$ Neurosci 5:915-926

Oertel D, Wu SH, Garb MW, Dizack C (1990) Morphology and physiology of cells in slice preparations of the posteroventral cochlear nucleus of mice. J Comp Neurol 295:136-154

O'Leary SJ, Tong YC, Clark GM (1994) Neural processes in the dorsal cochlear nucleus of the anaesthetised cat investigated from unit responses to electrical stimulation of the auditory nerve. Hear Res 74:181-196

O'Leary SJ, Tong YC, Clark GM (1995) Responses of dorsal cochlear nucleus single units to electrical pulse train stimulation of the auditory nerve with a cochlear implant electrode. J Acoust Soc Am 97:2378-2393

Paolini AG, Clark MG (1998) Intracellular responses of the rat anteroventral cochlear nucleus to intracochlear electrical stimulation. Brain Res Bull 46:317-327

Pfeiffer RR (1966) Classification of response patterns of spike discharges for units in the cochlear nucleus: tone burst stimulation. Exp Brain Res 1:220-235

Rhode WS, Greenberg S (1992) Physiology of the cochlear nuclei. In: Popper AN, Fay RR (eds) The Mammalian Auditory Pathway: Neurophysiology. Springer, Berlin Heidelberg New York, pp 94-152

Rhode WS, Oertel D, Smith PH (1983a) Physiological response properties of cells labelled intracellularly with horseradish peroxidase in cat ventral cochlear nucleus. J Comp Neurol 213:448-463

Rhode WS, Smith PH, Oertel D (1983b) Physiological response properties of cells labelled intracellularly with horseradish peroxidase in cat dorsal cochlear nucleus. J Comp Neurol $213: 426-447$
Romand R, Avan P (1997) Anatomical and functional aspects of the cochlear nucleus. In: Ehret G, Romand R (eds) The central auditory system. Oxford University Press, New York, pp 97191

Rouiller EM (1997) Functional organization of the auditory pathways. In: Ehret G, Romand R (eds) The central auditory system. Oxford University Press, New York, pp 3-96

Rouiller EM, Ryugo DK (1984) Intracellular marking of physiologically characterized cells in the ventral cochlear nucleus of the cat. J Comp Neurol 225:167-186

Rubinstein JT, Wilson BS, Finley CC, Abbas PJ (1999) Pseudospontaneous activity: stochastic independence of auditory nerve fibers with electrical stimulation. Hear Res 127:108-118

Shepherd RK, Javel E (1997) Electrical stimulation of the auditory nerve. I. Correlation of physiological responses with cochlear status. Hear Res 108:112-144

Shepherd RK, Javel E (1999) Electrical stimulation of the auditory nerve. II. Effect of stimulus waveshape on single fibre response properties. Hear Res 130:171-178

Shofner WP, Young ED (1985) Excitatory/inhibitory response types in the cochlear nucleus: relationships to discharge patterns and responses to electrical stimulation of the auditory nerve. J Neurophysiol 54:917-939

Stypulkowski PH, Van den Honert C (1984) Physiological properties of the electrically stimulated auditory nerve. I. Compound action potential recordings. Hear Res 14:205-223

Van den Honert C, Stypulkowski PH (1984) Physiological properties of the electrically stimulated auditory nerve. II. Single fiber recordings. Hear Res 14:225-243

Van den Honert C, Stypulkowski PH (1987) Temporal response patterns of single auditory nerve fibers elicited by periodic electrical stimuli. Hear Res 29:207-222

Wan XS, Liang F, Moret V, Wiesendanger M, Rouiller EM (1992) Mapping of the motor pathways in rats: c-fos induction by intracortical microstimulation of the motor cortex correlated with efferent connectivity of the site of cortical stimulation. Neuroscience 49:749-761

Wilson BS, Finley CC, Lawson DT, Wolford RD, Eddington DK, Rabinovitz WM (1991) Better speech recognition with cochlear implants. Nature 352:236-238

Wilson BS, Finley CC, Lawson DT, Zerbi M (1997) Temporal representation with cochlear implants. Am J Otol 18:S30-34

Wu SH, Oertel D (1984) Intracellular injection with horseradish peroxidase of physiologically characterized stellate and bushy cells in slices of mouse anteroventral cochlear nucleus. J Neurosci 4:1577-1588

Zhang S, Oertel D (1993) Giant cells of the dorsal cochlear nucleus of mice: intracellular recordings in slices. J Neurophysiol 69:1398-1408

Zhang S, Oertel D (1994) Neuronal circuits associated with the output of the dorsal cochlear nucleus through fusiform cells. J Neurophysiol 71:914-930 